\title{
Erratum to: Reference genes for transcriptional analysis of flowering and fruit ripening stages in apple (Malus $\times$ domestica Borkh.)
}

\author{
Pâmela Perini • Giancarlo Pasquali • Márcia Margis-Pinheiro • \\ Paulo Ricardo Dias de Oliveira • Luís Fernando Revers
}

Published online: 13 May 2014

(C) Springer Science+Business Media Dordrecht 2014

\section{Erratum to: Mol Breeding DOI 10.1007/s11032-014-0078-3}

Unfortunately, one of the co-authors' name was published incorrectly as Paulo Ricardo Dias de
Oliviera. The correct name is Paulo Ricardo Dias de Oliveira.

The online version of the original article can be found under doi:10.1007/s11032-014-0078-3.

P. Perini · G. Pasquali · M. Margis-Pinheiro Programa de Pós-graduação em Biologia Celular e Molecular, Centro de Biotecnologia, Universidade Federal do Rio Grande do Sul (UFRGS), P.O. Box 15005,

Porto Alegre, RS CEP 91501-970, Brazil

M. Margis-Pinheiro

Departamento de Genética, Núcleo de Genômica, Funcional de Plantas, UFRGS, P.O. Box 15053, Porto Alegre, RS CEP 91501-970, Brazil

P. R. D. de Oliveira · L. F. Revers $(\bowtie)$ Laboratório de Genética Molecular Vegetal, Embrapa Uva e Vinho, Rua Livramento 515, P.O. Box 130, Bento Gonçalves, RS CEP 95700-000, Brazil e-mail: luis.revers@embrapa.br 